\title{
THE RELATION BETWEEN CHEATING AND STUDENTS ETHICS
}

\author{
Asma Khaleel Abdallah \\ Assistant prof. Dr, Abu Dhabi University, United Arab Emirates, asma.abdallah@adu.ac.ae
}

\begin{abstract}
Cheating is said to be one of the most underlying issues in the colleges. The attitude of the students concerning to cheat is mostly created in the high school where the students initiate with seeking for the ways to cheat. As per the recent study done, it was revealed that many of the students perceive the criteria of success as having a good grade which enforces them to cheat and go for the option of cheating rather than graduating with integrity. This, as a result, lead to academic dishonesty among the students that are being credited to work that is not their own. Keeping this in view, the following research will aim to discover the association among the cheating and students' ethics at the university. This has been taken into account by means of sampling method. Moreover, the study will look to understand that if the students are aware of the honor code of the concerned university and either they follow it or not. In order to undertake the research, the researcher has taken a total of 250 students were taken as the target audience from different universities in order determine the occurrence of cheating on the ethical standards of the students and mainly to know the root cause behind cheating and the fact that how students perceive cheating with respect to academic ethics. The results showed that 25 percent of the students viewed cheating as copying of other's work, while 17 percent thought to cheat as violating the academic rules. Despite accomplishing the objective, the study is still bound to some limitations which creates a gap to be fulfilled in future that is the limited sample size. Therefore, future researchers are suggested to consider the big sample size for the future study.
\end{abstract}

Keywords: Cheating, Ethics, Plagiarism.

\section{OVERVIEW}

In recent years, research has indicated that cheating is becoming more prevalent in colleges than ever before. The behavior to want to cheat is mostly developed in high school, where students begin to look for ways in which they can cheat. However, cheating is mostly attributed to the belief of what success is all about. According to a recent study, many students said they measure success in terms of having a passing grade for the purpose of graduating rather than the integrity of completing a course without cheating. This amounts to academic 
dishonesty that leads to students being credited to work that is not their own. Some may receive unauthorized assistance in their academic work, while others may be credited for plagiarized work.

In a survey done in the year 2012, $80 \%$ of students interviewed confessed to having cheated in exams. Most of them mentioned being assisted in doing their exams from outside sources, where they someone would do the assignment for them. Some of them acknowledged that they began cheating even before they enrolled in college. This means that cheating is an ethical behavior that starts so early in education, where students begin contemplating how they can be successful. The cheating rate is very high within the education system that around $95 \%$ of those interviewed admitted that they were never caught. This gives them confidence that they can continue to cheat without having to worry about ever getting punished for it.

Cheating and academic dishonesty have been there for many years, as has been reported by many research works. However, as technology advances, cheating changes in character, making it hard for students to be discovered. Plagiarism and aided cheating are becoming common as technology advances. Data provided shows that in as much as there is a very number of students involved in academic cheating, disciplinary cases are very few. This means as mentioned earlier, academic dishonesty is not being punished because students are not being caught. This is because students are devising techniques to cheat that has become very hard for the education system to detect them.

\subsection{Background}

This particular research will explore the relationship between cheating and students' ethics at the university, by sampling data from students. The research will seek to understand if students are aware of the honor code of their specific university and whether they adhere to it. In this research, a total of 250 students was involved from different universities to ascertain the prevalence of cheating and ethical standards of students. Most importantly, students moral reasoning as key in establishing cheating and their view in regard to academic ethics will be reviewed.

This research made sure that the representation is widespread to make sure that data collected will be credible and give the exact situation of the relationship between cheating and students' ethics. This will include collecting data from a diverse correspondent where critical factors are considered such as age, gender, race, religion, and social economic status. The essence of these factors is to guide the research in a manner that it will handle all people in their different social class, race, religion, and gender. More so, this research will not be concentrated only within one institution, but various so that it can be represented.

\subsection{Research Aims and Objectives}

This study seeks to understand the relationship between students' moral reasoning on academic integrity and their adherence to "honor code" of their particular college, which is normally designed to enable students to uphold academic integrity. It is the interest of this study to explore their specific moral reasoning that guides their actions that largely leads to academic integrity. It is of the essence to understand the moral development of the students' academic integrity or lack thereof. In order to successfully understand their moral reasoning, this study will attempt to examine why they decide to cheat on exams. The aims of this study are diverse. Firstly, this study aims at gaining more knowledge on the moral development of the students, especially within learning institutions, despite there being the code of honor to guide them of academic integrity.

\subsection{Research Questions}

This research came up with three questions to make the research achieve its intended results;

1. How do participating students define cheating?

2. Why do the students cheat?

3. What are The kinds of cheating taking place?

4. What are students Attitudes towards cheating?

\subsection{Rationale of the Study}

As stated earlier in this study, there are compelling reasons to believe that cheating among college students has increased in the recent past. Cheating among students reduces the integrity of the education system, thereby 
making who do not deserve a certain grade being awarded the grade. The ability to cheat has been escalated by the fact that it has become too easy to cheat, which of course aided by the influx of technology. Ethical standards, on the other hand, are reduced during cheating, where a student may transfer that to the work environment, where one may believe that the way to achieving what one wants on life is through dishonest gain.

It has been widely accepted that students cheat because there is the idea that one's success is measured by the grades achieved through the education sector. There is often no mention of the integrity in earning one's grades. This means that a student will do anything to cheat without getting concerned about the integrity in their actions. As has been mentioned earlier in this study, a very high number of students accepted to have cheated on their exams. This is worrying in that only a small fraction of them was actually caught and punished. The rest no one knew they had cheated to earn good grades.

Cheating is practiced in the full knowledge of the honor codes of a learning institution, where students are introduced to them during enrollment. As is the practice of every learning institution, honor codes are introduced to make sure that students adhere to rules of learning. They sanitize education by making sure that students are awarded the graded that is rightfully theirs. Nonetheless, many students are not getting caught while cheating and if this trend is allowed to continue, lack of integrity will be transferred into the workplace or any other occupation.

\subsection{Significance of the Research}

This study finds that it is of great importance to understand the relationship between cheating and student ethics. Questions that relate to cheating are answered with the hope of unearthing the much-needed knowledge on exam cheating. More so, this research aims at establishing the why students cheat yet they are fully aware that what they do is wrong according to education ethical expectations. Once all the underlying factors have been established, then it becomes easy to solve the issues that revolve around cheating. Technology is meant to help in education, but students are now using the same technology to cheat in their education. It is very important to not the reasons and help in changing students' perceptions.

The significance of this research is to establish a connection between students' ethics in relation to cheating. When students cheat in such an alarming rate, it shows a lot about the ethical fabric of the education system, where the students, as mentioned earlier, may go ahead and transfer the behavior. This study will help to understand the convictions of students as such decisions to cheat. Once this is well established, it becomes easy to curb the vice. Helping students understand the value of adhering to ethical standards in the ultimate desire of this learning, where a student is made to know and learn the importance to honor codes.

This study understands that cheating is more prevalent in the college level of education, where it has been widely believed that students begin cheating from high school. Once the study is complete, students can be assisted in understanding the importance of ethical standards while learning. On the other hand, cheating should be made to be very hard in that students are discouraged from it. This will make sure that the grades awarded will purely reflect the independent ability of each student, where relevant steps should be taken should it be established that learning has gone down, or ethical standards have been neglected.

\subsection{Data Collection}

For this particular project to be complete, data came from students from various university students. A random sample of 250 students was selected for this study. To enable this study to attain true reflection on the ground, this study looks at various students from different universities, where some of them have confessed to having cheated on their exams. This study seeks to collect data by asking the student to answer survey questions and write on 4 X6

index card, "What is cheating?. This will help in establishing where cheating is most prevalent. Equally, this will assist in knowing the reasons as to why students cheat. Data collected sampled to come up with a dependable analysis of the problem facing the education system.

\section{LITERATURE REVIEW}

\subsection{Moral Development}

Shrader et al. (2012) observe that moral development is well promoted within a college environment, more so because of the honor code that is evident in each college as a rule. In this area of moral development, the 
research is keen on looking at perceptions that students have in regard to moral judgment. More so, this portion looks at the student's interpretation of the honor code in their respective colleges. This will guide this study in understanding why they cheat on their exams. It has been established that moral judgment can be defined as a psychological construct, where the mind processes the information between what is right and what is wrong (Harding, Finelli, \& Carpenter, 2006). Moral judgment is informed by particular moral issues at hand, the perception of an individual towards moral standards and the actions that one determines to take in the full understanding of these moral standards.

Kaufman (2008) observers that moral judgment involves a lot of underlying factors that may make a person make decisions that are against one's convictions. This involves pressure from society like parents, teachers, and the reality in real life where grades are believed to determine one's success or failure in life. In as much as a student might be fully aware of the honor codes, the threat of being branded a failure and the fear of never getting the ability to advance to higher education and never getting a good job is enough pressure to make a student attempt cheat.

While researching on students' ethical perceptions, Colnerud and Rosander (2009) found out that the progression of moral development is largely determined by one's interest for a better performance. This can be out of self-interest or pressure from the public. As mentioned earlier in this study, this could be because of pressure from the public has been recorded among public personalities who wanted to remain on top but their abilities could not allow the and so they had to cheat. Many psychologists have argued that if ones moral development is no shaped from a young age, the probability of such a person becoming dishonest if very high later on in their lives.

\subsection{The integrity of Academic Systems}

Academic systems are governed by rules and regulations which, make sure that the integrity of academics is preserved and well taken care of. Without academic integrity, education wouldn't mean much because that would mean that credibility would be put into question. Colnerud and Rosander (2009) found out that every student is made aware of the honor code of their respective institutions, yet they chose to cheat on their exams. In their quest to find the reasons that make students cheat, Colnerud and Rosander (2009) discovered that students have a misunderstanding of success that is largely influenced by society. These particular misunderstandings are created by the society which expects them to perform excellently in their exams as a measure of success.

The academic systems are well organized and there a lot of transparency and integrity in almost every learning institution. Nonetheless, there are institutions that do not have honor codes and students in those institutions view them differently. As Kocanjer and Kadoic (2016) found out, honor codes have a lot of influences in students' behavior in that they will always be inclined to do that which is right as guided by the honor code. On the other hand, students in institutions that do not have honor code were found to have different views about academic integrity. This is because there are other outside forces that inform them what academic integrity is. Kocanjer and Kadoic (2016) explain further that students guided by honor code are more responsible and feel significantly responsible in regard to academic integrity.

\section{CONCLUSION}

Cheating in the education system throughout the United States has become prevalent in a big way, aided by technology and the internet. Students are always looking for ways in which they can cheat and be awarded grades that are not their own. This has lead to lowering the integrity in the academic field, where moral development mostly takes place. In high school, as is evident in the above literature review, this is the place that many students learn or acquire the behavior to cheat. Influenced by the internet, the urge to succeed, and the pressure from society to become the best, the lure of cheating overtakes their academic integrity. Notably, even the honor code in colleges can sometimes not work for the students who are determined to cheat.

\section{RESEARCH METHODOLOGY}

\subsection{Research Process}

In order to achieve the intended results, this study seeks to apply various forms of approaches to collect data pertaining to the research question. Here, both qualitative and qualitative procedures are used. In all the 250 students answered the survey questions and answer "what is cheating"?. This is a relevant way to measure 
student's moral judgment on issues of great concern as cheating. More so, this survey was able to reveal how students from various moral development levels interpreted or viewed honor code of their respective universities.

Because of the nature of the research question, this study used a mixture of approaches. Focusing on a research done by Vivian M. Corll (2007), she linked the research to a more mixed method, where she was able to get precise answers to the research question. As this study was much more interested in the relationship between cheating and students ethics, a quantitative approach was applied. This was relevant in measuring their moral reasoning. The survey was then applied in order to collect data from students on various levels of moral reasoning. This procedure enabled the research to determine if there was any relationship between students' ethics in their different levels of moral development and cheating. More so, this assisted in the research establishing their version of the honor code and ethical standards.

\subsection{Research Design}

There were three major designs that this study embarked on. Firstly, descriptive design was applied because this would help this study record various assessments as were stated by the correspondent. Additionally, the exploratory design came in handy because some of the students would perhaps give the wrong account or would not fit the research. This led to some of the research being expunged from the final report because of their lack of authenticity. This research design made sure that the data collected was effective for use.

\subsection{Data Collection}

The design of this research was targeted at 250 students from different universities, This was to make sure that the data collected was evenly distributed from various places so that various levels of moral development can be measured. More so, when data is collected from different institutions and various levels, it becomes easy to analyze that data and come up with a dependable finding and a true representation from the ground. The research targeted 250 students from different universities. All students required to take the survey questions.

For the students in the university, the research did not want to target students only on a specific course or major but spread across all spheres of study. This was meant to ascertain that notion that students with a specific major are the ones who are prone to cheating because the subject is hard. A variety of majors were represented at the university level. Additionally, the research made sure that there is a variety of diversity that is race, age, gender, and social backgrounds.

It was a very effective process that brought out the desired reading of the relationship between cheating and ethics among students. The respondents were very keen on the questions asked and the responses reflected genuine perceptions of the respondents. Also, students' level of reasoning was satisfactory to the desire of the research.

\subsection{Sampling}

To make sure that data was well documented, students were categorized into various groups, where their data were stored in regard to their specific characterization. For example, in the university category, the data collected was categorized dependent on issues like the course one is taking, age, social background, social economic status, race, religion, and gender. This way, the research was able to come up with a well-organized data that could be analyzed effectively. The community was 750 students and total sample number was 250 students.

\subsection{Data Analysis}

Data analysis was done to make sense of the information gathered during the interviews. As Goodwin (2015) suggested, there are various ways of analyzing data to make sense of the sampling used. Firstly, after data collection technique was ascertained, then there was the data interpretation stage to make sure that the information given was well understood. More so, there were data collected that this study didn't feel met the criterion and so some of them were expunged from the study during analysis. Some of them displayed inconsistency while giving out their information during the qualitative interviews.

For the descriptive statistics, the survey has preferred to have some questions that would be measured by means of the nominal scale, ratio scale and the ordinal scale. A nominal scale is defined as the one which is used in recognizing the traits and aspects (Creswell, 2005). These aspects cannot be measured through ranks like small to large (Noursis, 2000) as compared to the nominal scale which includes questions related to gender and time frame spent in the university and questions with the options of yes or no. The ordinal scale, on the 
other hand, is the one that specifies about the order and ranking, however, the association among the two is meaningless. For instance, the question below on the survey is the example of the ordinal scale: The act of cheating in the university is 1 . Never wrong 2 . Usually wrong 3 . It is fine in case if the teacher is not good 4 . Yes, if the teacher shows no concern about cheating 5. Always wrong. Lastly, the scale of the ratio is defined as the one where the study can tell about the extent of smaller and larger as compared to the other (Norusis, 2000). Such as the survey included questions related to the estimation of students who have cheated in the current school or college and the range is set to answer the question.

\subsection{Validity}

Every research work must have dependable ethics to make sure that the data collected reflected the true situation on the ground. Credibility and trustworthiness of this study were put into consideration from the initial preparation to make sure that the research meets all the required criterion of integrity. The data collected was ensured to reflect the descriptive view of the correspondent. Equally, it was made sure that correspondents were not aided in answering questions or giving out their answers. More, it was made sure that students fully understood the questions asked so that answers given can reflect some who truly understood the questions clearly.

\subsection{Ethical Considerations}

Since this study involved ethical issues in academic integrity, we made sure that there was the promise of confidentiality of the correspondents. This enabled the students to give a true account of information without having to worry about their information reaching a third party. In the final report, pseudonyms names were used to completely conceal their identity. This masked their identity as had been agreed. The record of all the research done in the field work is not accessible to a third party and the policy is to destroy it once the research work is finally done.

\section{DATA ANALYSIS AND RESULTS}

While drawing the results, there were two main instruments that were used to demonstrate the status of the student's ethics. The first instrument was the survey which was a five by seven-inch index card where the students were asked to give their opinion about cheating and how they perceive the term subjected to the act of cheating. The question that was asked was, "What is cheating. While conducting the survey, all the respondents were kept anonymous for privacy reasons.

\subsection{Analyzing the Cards Results}

From the analysis of the cards, it was observed that 25 percent of the students prompted cheating as an act of copying someone else work, 17 percent of the students, on the other hand, define the idea of cheating as the act of breaking the rules and 16 percent of them described cheating as helping the friends. There was 15 percent of the respondents who perceived cheating as a kind of shortcut in order to make the life easier and 13 percent students labeled cheating as using the illegal help. The remaining 11 percent perceived cheating as taking an unfair advantage and the last 3 percent respondents stated cheating as stealing an act of theft.

\subsection{Results of the Survey}

The survey that was taken to highlight the descriptive statistics as a snapshot of the cheating attitude among the targeted audience of the university. The survey has covered the four following topics.

- The students who involved in the act of cheating at any time of their school life and their explanations regarding the topic.

- The different types of cheating taking place on the premises.

- The behavior of the targeted audience towards the idea of cheating.

- Lastly, knowing the peripheral factors outside the university that also serve in the cheating behaviors.

\section{The Survey}

Total of 250 respondents was gathered from the general audience of the university. Majority of the students were identified with having average academic skills which were evident by the self-reported grade point average. 
Following is the analysis of the questions and the answers given by the respondents:

\section{Question: I have noticed the occurrences of the cheating at the time of tests in the previous times.}

$52 \%$ of the students of the university have experienced cheating while the test more than one times. However, 48 percent of them have never been into the experience of cheating.

\section{Question: As per my estimation, the ratio of students who have cheated in my college is?}

36 percent of the students claimed that cheating has taken place to some extent in their campuses.

\section{Question: The most important reason behind my cheating is}

- I should get the higher grades to have a career progression in the school.

- I want to fulfill my parent's expectations

- I will be punished in case of not getting good grades.

- I do it for fun. It shows a challenge

- I don't perceive any association among what I expected to learn and my future.

- None of the above. Please explain

One of those who responded with the none of the above options were $64 \%$ of the total students while the other gave the statement that they don't cheat by quoting the following reasons:

1. I want to retake the class that is why I cheat.

2. I can not accept a lower GPA that is why I cheated once.

3. The teachers also don't teach the sufficient material due to which I am not able to do the test.

4. Being an adult, I need to pass the classes for the promotions.

5. I was not prepared completely that is why I cheated

6. Cheating is never an option to achieve something in life. The test was difficult and had no time to research so I borrowed my friend's paper.

From the above statements if the students, it can be demonstrated that the ends validate the means and if an individual has a greater need, he or she will perceive cheating as a shortcut and the only option.

\section{Question: If there will be cheating going on in the class, will I inform the teacher?}

$88 \%$ of the students stated that they have never informed their instructor about the act even if they evidenced it informed of them the reasons behind not telling the instructor were being fearful, being under the peer pressure or being anxious about how the instructor would manage the situation.

The other questions of the survey were subjected to the types of cheating one has got indulged into. The answer to this involved the use of cheat sheets and the use of electronic devices.

Question: I have made use of cheat use of the cheat sheets within the past years

The options under this question involve crib sheets, notes on the soda water and water bottles and the notes written on hand. The respondents were asked about the number of time they had been into this kind of cheating.

The results showed that about 16 percent of the students used the cheat sheets in the past years while most of the students were noticed in using the cheat sheets.

\section{Question: I have made use of electronic devices to cheat at the time of class tests or assessments.}

The answer to this question implied that only 18 percent of the students have used the electronic card sheets to cheat in their past types. On the other hand, the students of social media were observed using the cell phones and graphing calculators to cheat. 
Question: I have use plagiarized essays and/or research papers by taking help from the Internet or print sources and turned them in as my own work.

As per the analysis, $28 \%$ of the students stated that they have copy pasted the work from the internet and from the printed sources. Thus, most of the students have not copy-pasted from the internet.

Question: I have bought essays and research papers from one or more of the Internet sites that sell papers.

The tabular analysis showed that $19.2 \%$ of the papers have been bought from the internet. Out of the 250,13 respondents stated that they have indulged into this type of cheating multiple types and the eight of the students asserted to be involved even more than more than five times in the activity.

Question: Within the past year, I have taken of from the class at the day opf test in order to get the additional days to study and to find out from other what is on the test.

Under this question, 18 percent of the students have used the absenteeism approach as a form of cheating while 82 percent of the respondents did not use this method of cheating.

Question: Within the past year, I have been able to convince the instructor that it is his/her fault that my project is not submitted on time due to some "teacher error," when, in fact, I was not prepared.

Among the sample size, 20 percent of the respondents demonstrated that they have convinced the instructor in admitting that it was their mistake behind the late submission of the project and 80 percent of the students have been given the blame.

Question: Cheating at university is...

The analysis showed that 8 percent of the students perceived cheating as not a wrong act and the remaining 82 percent of the respondents agreed that cheating is always an act of misconduct

Question: Have I ever cheated during the test or assesment that would result in a grade during my school and university career.

Among the 250 students, $96 \%$ of the students admitted to doing cheating sometimes while the time of university careers.

Question: Within the past year207-2018, I have copied another student's homework, class work, essay, or report and turned it in as my own work about how many times?

The analysis demonstrated that 72 percent of the students admitted about copying the work from other students in the past years.

Question: Plagiarism is...

68 percent of the students declared that the act of plagiarism is always wrong and 22 percent of the students justified the idea of plagiarism as fair in some of the situations. There were only 25 students that declared plagiarism as a fair act.

Question: I have hired someone to do my essays and projects.

$2 \%$ percent of the students admitted that they have paid someone to do the essays and the projects. Students were reported to use the power of money six to more than six times.

\section{Question: The new smart phones and watches are added enticement for cheating.}

52 percent of the students responded with the yes answer to the question, however, 110 students answered with no. On the other hand, the medical students illustrated that incentives like smartwatches and cell phones were of no use to cheat.

Question: While growing up, my parents/guardians contributed to put emphasis to demonstrate the differences between right and wrong and guided me to behave morally.

To this question, 83 percent of the students responded that it is the parents who played put stress on the students to identify among the right and wrong, good and evil and parents and guardians are the ones who teach to behave morally. 30 students demonstrated that they were being taught about right or wrong frequently. 
Nobody preferred the option of never under the third question.

\section{SUMMARY AND DISCUSSION OF RESULTS}

\subsection{Lessons Learned from the Results of This Study}

The results have shown that the present study has contributed significantly to presenting the paradox in the student ethics area. The findings revealed that the students, despite being intelligent, indulge themselves in the unethical practices and making themselves the victim of the other, however, each one is the committer. If we see it from individual perspectives, one is full but if we see collectively, all the people indulged will be considered guilty. The test conductor would even be termed as guilty if he would not report the dishonesty taking place in the premises. The majority, of the respondents in the study, have identified that the situation at which the option of cheating is pursued is not under their control and they feel it a risk to cheat but are more fearful of losing if they don't cheat.

With this in mind, it can be demonstrated that the young people being entangled in this paradox are in need of some extraneous factors that help them to get themselves detached from this act of academic dishonesty. The most important people that can contribute to saving the students from this entanglement are teachers, instructors, and their administrators. Hence, below are the findings codified and explored from the examination of the proposed study on the behavior of cheating:

1. There is an essential number of students who are indulged in cheating and that as a result culminates into creating problems for the feasibility of the assessments.

2. The root cause of cheating is the intense pressure that is on the students, particularly in the case of elite students who have the additional pressure from their parents, teachers and the universities GBA.

3. The practice of cheating and plagiarism take place at the school times and with the passing time the behavior gets acceptable among the students. The fear of expulsion leads them to cheat most of the time.

4. The students at high school plagiarise the work as there is no use of software for the detection of copypasted work which makes cheating rampant among the students.

5. The drivers that can contribute to erasing the cheating behavior among the students are as follows:

a) 100 percent probability of being caught and punished while cheating

b) A civilized environment in the high schools that should not in any way tempers the consistency of punishment.

- One of the essential element is that the teachers to show genuine love and care for every student and eliminate biases among the students. Moreover, they should also restrain themselves from deliberating about the how-many-days and before-i-can-retire discourse.

- The administrators are required to model the high school to act more like the universities and implement and develop the small learning communities. A student should not be considered as the component in the huge wheel of education, but they should be preferred as a living human with hopes and fears and most essentially be nurtured to unleash the talents.

- One more essential step that needs to be taken is to eliminate the line among the instruction and assessment by interpreting the idea of cheating as archaic.

- Finally, the last strategy to should be implemented to have a performance-based assessment rather than examination based.

Hence, from the analysis, the conclusion can be drawn that rearranging the high schools is not an easy task, though the educator should take the start from somewhere. It might be implemented from one classroom where the teachers coordinate with the students every day. Therefore, the stronger foundations with respect to eliminating this behavior can be helpful in keeping a fertile hill form turning into the dust bowl. 


\section{REFERENCE LIST}

Kocanjer, D., \& Kodaic, N. (2016). Raising Students' Awareness of Ethical Behavior. Retrieved from, https://bib.irb.hr/datoteka/822680.Raising students aware.pdf

Shrader, B, Ravenscroft, S., Kaufmann, J., \& West, T. (2012). Classroom Cheating and Student Perceptions of Ethical Climate. Retrieved from, https://lib.dr.iastate.edu/cgi/viewcontent.cgi?article=1007\&context=management pubs

Harding, T., Finelli, C., \& Carpenter, D. (2006). Cheating in University and Influence on Ethical Behavior in Professional Engineering practice. Retrieved from, https://digitalcommons.calpoly.edu/cgi/viewcontent.cgi?referer=https://www.google.com/\&httpsredir=1\&arti $\underline{\mathrm{cle}=1057 \& \text { context }=\text { mate fac }}$

Kaufmann, H. (2008). Moral and Ethical Issues Related to Academic Dishonesty on College Campuses. Journal of University Character. Retrieved from, https://www.tandfonline.com/doi/pdf/10.2202/1940-1639.1187

Colnerud, G., \& Rosander, M.(2009). Academic Dishonesty, Ethical norms, and Learning. Linkoping University Post Print. Retrieved from, http://liu.diva-portal.org/smash/get/diva2:275301/FULLTEXT01.pdf

Dickey, S. (2015). The Relationship Between Ethical Regard and Academic Misconduct Among College Students. Dissertation. Retrieved from, https://dc.etsu.edu/cgi/viewcontent.cgi?article=3963\&context=etd

Goodwin, A. (2007). Exploring the Relationship Between Moral Reasoning and Students' Understanding of the Honor Code at the University of Maryland. Dissertation. Retrieved from, https://drum.lib.umd.edu/bitstream/handle/1903/7316/umi-umd-4719.pdf?sequence $=1$

Corll, Vivian M. ( 2007). Cheating, Plagiarizing, and false excuse making: a study in student ethics. Dissertation. Capella University.

Kurtz, H. (2006). Oprah throws the book at herself. The Washington Post, p. A01.Retrieved from, https://www.americanprogress.org/issues/general/news/2009/11/12/6982/think-again-the-neverendingscandal-of-howard-kurtz-and-the-washington-post/ 